\title{
A Strategic Approach to the Effectiveness Evaluation of Higher Education Curricula: Implications for Medical Education
}

\author{
Jafar Torkzadeh ${ }^{1}$ and Fahimeh Keshavarzi ${ }^{1,{ }^{*}}$ \\ ${ }^{1}$ Department of Educational Administration and Planning, School of Education and Psychology, Shiraz University, Shiraz, Iran \\ "Corresponding author: Department of Educational Administration and Planning, School of Education and Psychology, Shiraz University, Shiraz, Iran. Tel: +98-9176975529, \\ Email: fahimehkeshavarz@yahoo.com
}

Received 2018 July 19; Revised 2018 November 03; Accepted 2018 November 04.

\begin{abstract}
Context: The present study used a strategic approach to develop a conceptual framework for evaluating the curriculum effectiveness, which appears not to be limited to the internal dimension as far as the strategic approach is concerned as a comprehensive, environment-based and future-oriented method including both external and institutional dimensions.

Evidence Acquisition: Given that the available information about the effectiveness of medical education curriculum based on a strategic approach is institutionally qualitative, multidimensional and consequential, exploring, extracting and analyzing the related data requires using a qualitative model for dealing with the diversity of resources and information. A review of literature suggested that the cyclical process of analysis is a qualitative research method with the required characteristics consisting of the following phases: (1) Data collection process, (2) data reduction, (3) data organization and analysis, and (4) conclusion (interpretation and conclusion). Triangulation was used to validate the findings of the research method.

Results: Certain components of the effectiveness evaluation of medical education curriculum based on a strategic approach include achieving the internal goals of curriculum, satisfying the requirements of the internal environment through curriculum implementation, developing students' knowledge, attitude and skills, the internal coherence and consistency of the curriculum and the internal quality of the curriculum. These components also include fulfilling the goals, social acceptance of the curriculum, significant roles in social development, national self-sufficiency, proper performance and the education system reforms, improving the external image, and the strategic success of medical education curriculum.

Conclusions: The results of these comprehensive strategies include knowledge and skill adjustment, professional responsibility, spirit of accepting the change, flexibility, adaptability to the varying environment, optimal use of resources, and receiving feedbacks on the effectiveness of the implemented programs to modify or clarify the goals or strategic selections and decisions.
\end{abstract}

Keywords: Curriculum, Curriculum Evaluation, Curriculum Effectiveness, Strategic Approach, Medical Education

\section{Context}

Institutions are being increasingly urged to make plans to deal with the developments associated with the growing changes and dynamics of the environment. As an important and constructive social institution responsible for promoting creativity, empowerment and comprehensive development of the community, medical education systems have undergone considerable changes in recent decades. To maintain its dynamism, this institution requires strategic planning, process improvement and adoption of appropriate methods $(1,2)$, a policy with consequences that affect the performance of medical education institutions. Curricula constitute a major component or subsystem of medical education that must be strategically and effectively addressed. Policymakers at universities and medical education institutions must adopt different methods and strategic measures to develop curricula and adapt to environmental changes and satisfy the current needs of the community. Curricula are the undeniable heart of higher education systems that reflects the latest human accomplishments in different scientific fields and transfers these accomplishments to future generations. Curricula should therefore meet the changing environmental needs, including the community and its different segments, thereby helping universities to survive $(3,4)$.

Many researchers have studied the challenges and curricula of medical education (5-13). Some instances suggest that actual mission of higher education curricula has not been fulfilled, including underrating the importance of curriculum development, unfamiliarity of faculty members with curriculum development even in the field 
of humanities, excessive focus on current conditions and needs of curriculum development while neglecting scholarly foresight, inconsistency of curricula with labor market demands and failure of the curricula to help students gain the necessary information and skills needed for playing an effective role in the labor market (14). Deliberation over the cited issues reveals the necessity of taking fundamental measures in the area of medical education, especially for the effectiveness of medical education curriculum as a major component. In fact, medical education must gain knowledge about and identify the changes in the internal environment and its components and create the changes required for maintaining its dynamic entity. These changes, however, should consistently involve all the components and maintain their logical connection, including the goals, responsibilities, structure and plans (14).

Given that strategic approach always seeks to ensure the overall proportion between the system, i.e. curriculum, and the current and future environmental conditions and requirements, adopting such an approach actually constitutes a new perspective of medical education curriculum. From this perspective, the system must survive and be able to respond to the future environment and fulfill its goals. The effectiveness of the curricula is therefore defined as the internal, external and institutional dimensions within the environment. Moreover, responding to the environment is the ultimate criterion for preserving the curricula effectiveness. The present study seeks to examine the effectiveness of medical education curriculum owing to the major role of this component in fulfilling the goals and missions of medical education and given that different researchers and experts refer to curriculum as "the heart of medical education system" (2) or as a teaching/learning map and present comprehensive definitions for curriculum as a science (15). Focusing on this component definitely leads to fulfilling the goals and missions of medical education, i.e. human perfection. Evaluating the curricula effectiveness and the degree to which the goals and ideals are fulfilled in proportion to the environmental dynamics and complexities are therefore crucial, and cannot be realized unless an interdisciplinary approach to curriculum is adopted and the management literature and a strategic view are especially utilized.

Based on a review of literature and the models found for assessing the effectiveness of medical education programs, efforts were made in the present study to define a set of criteria for evaluating this component depending on the topics and using a strategic approach to the effectiveness of curriculum as a major component of medical education. Educating decent and competent individuals considering different personal, human, social, cultural and po- litical dimensions was also addressed as the mission of this program. Given the importance of this issue, the present research was performed to present a conceptual framework for examining the effectiveness of medical education curriculum using on a strategic approach.

\section{Evidence Acquisition}

Given that the available information about the effectiveness of medical education curriculum based on a strategic approach is institutionally qualitative, multidimensional and consequential, exploring, extracting and analyzing the related data requires using a qualitative model for dealing with the diversity of resources and information.

A review of literature suggests that the cyclical process of analysis (16) meets the requirements and consists of the following phases: (1) Data collection process, (2) data reduction, (3) data organization and analysis, and (4) conclusion (interpretation and conclusion). The mentioned phases in the cyclical process of analysis must be continuously considered in an interactive combination that leads to the discovery and creation of concepts and the significant development of new knowledge. The present study used this process until data saturation was achieved. The result of the present research was a set of specific concepts associated with the effectiveness of medical education curricula as the form of a conceptual framework obtained by using a strategic approach. Given the qualitative and dynamic, multidimensional and interactive nature of the data, data collection was conducted in an open and documentary fashion. The statistical population comprised the accessible documents in databases on evaluating the effectiveness of medical education curricula. The statistical sample was collected for analysis from these resources using targeted sampling. Springer, ScienceDirect, Ebsco, Emerald, ISI, Eric and Francis and Taylor were used to review the studies conducted outside Iran. Ninety scientific publications on the subject were studied and analyzed as the sample. Data collection continued until content sufficiency was achieved. Furthermore, the specialized keywords used to obtain the required information included curriculum effectiveness, curriculum evaluation, evaluation of curriculum effectiveness, strategic approach, medical education curriculum, and strategic medical education curriculum.

\section{Results}

3.1. The Effectiveness of Medical Education Curriculum Based on a Strategic Approach

This part of the research seeks to identify the effective components associated with different dimensions of med- 
ical education curriculum, i.e. internal, external, and institutional components.

\subsection{What Are the Components Associated with Evaluating the Internal Effectiveness of Medical Education Curriculum from a Strategic Approach Viewpoint?}

The internal effectiveness of curriculum refers to the internal proportion and coherence of different parts of the curriculum necessary for fulfilling the desired goals. Internal goals include coherence and proportion between dimensions and components of curriculum such as the proportion between content and educational goal, proportion between content and teaching method, proportion between content and evaluation as well as dynamic learning environment, quality of science, quality of teaching, teachers' attention to students, available resources, students' satisfaction with the curriculum, professional and research activities of the faculty members, evaluation and testing, resource accessibility, and involvement of faculty members. The internal effectiveness of the curriculum will be ensured if curriculum experts consider the emphasized dimensions and components and effectively play their roles during the phases of design, development, implementation and evaluation of the curriculum. According to the above cited matters, the internal effectiveness of the curriculum is guaranteed, the goals are achieved and the current and future environmental requirements are satisfied through the interaction of different curriculum dimensions and elements. To better understand the internal quality of medical education curricula, a comprehensive list of effective curriculum components should be addressed based on the evaluated dimension of the internal effectiveness (Table 1).

3.3. What Are the Components Associated with Evaluating the External Effectiveness of Medical Education Curriculum from $A$ Strategic Approach Viewpoint?

External effectiveness is ensured when the goal (effectiveness) is fulfilled through changing the behavior and affecting the environment (16). External effectiveness refers to the efficacy of the learning in practical situations outside the teaching environment where the learner lives or works. In other words, the more the (external) learning associated with education leads to exhibiting the intended behaviors and results in the learners' functioning in practical situations outside the learning environment, the more effective the education will be(22). Medical education curriculum therefore appears to be externally effective when it can effectively meet the environmental needs and provide the necessary efficacy in practical situations outside the internal organizational processes. Under such circumstances, the three behavioral dimensions, i.e. knowledge, attitude and skill, manifest themselves and the adaptation of learning to the environment is facilitated (16). The components of the external effectiveness of medical education curriculum are therefore as follows in Table 2:

3.4. What Are the Components Associated with Evaluating the Institutional Effectiveness of Medical Education Curriculum from A Strategic Approach?

Institutional effectiveness is introduced at the macro level and refers to fulfilling the existence philosophy of the curriculum (16), i.e. the extent to which the organization activities lead to fulfilling the organization ideals in the community and playing an effective role in the process of national development and establishing positive relationships and changes (20). Institutional effectiveness therefore focuses on fulfilling the internal and external goals of medical education curriculum according to the basic ideals, i.e. vision, mission and values. In fact, the actual mission of medical education curriculum is to significantly maintain and sustainably develop educational institutions according to environmental conditions. Close and accurate coordination among the intended, implemented and acquired curricula ensures the effectiveness of medical education curriculum. Fulfilling the ideals, goals, content and teaching/learning methods and evaluation method of academic progress in a curriculum as a set of learning activities in classroom definitely ensures the internal and external effectiveness (Table 3). Institutional effectiveness is also the result or consequence of the internal and external effectiveness, and indicates the education system effect on fulfilling the organization missions (20) (Table 3).

In addition to the cited instances, other dimensions of institutional effectiveness of the curricula include developing educational technology, training specialized personnel, promoting public culture and moral virtues, extending the boundaries of knowledge, national development, adapting sciences to Islamic ideology, commercializing curriculum studies, improving national economy, enhancing international understanding and training competent specialists.

\section{Discussion}

Universities have an immediate contact with the outside environment, i.e. they affect and are affected by it $(1,2)$. In fact, the university system changes within the context of environmental changes. Understanding the past and current condition of the university is crucial for identifying its capabilities and weaknesses within the context of opportunities and threats, which makes it even more necessary 


\begin{tabular}{|c|c|}
\hline Dimension of Internal Effectiveness & Reference \\
\hline Fulfilling the internal goals of the curriculum & $(14,16-18)$ \\
\hline Satisfying the requirements of the internal environment when implementing the curriculum & $(16,19)$ \\
\hline Developing students' knowledge, attitude and skills & $(14,16,20)$ \\
\hline Students' academic success & $(19,21)$ \\
\hline Interactive environment for the beneficiaries (satisfaction, mood, teacher/student relationship, behavioral interactions) & $(16,21)$ \\
\hline $\begin{array}{l}\text { Internal coherence and adaptability of the curriculum (adaptability of the curriculum to the goals, content, teaching/learning method } \\
\text { and evaluation method) }\end{array}$ & (21) \\
\hline Flexibility and initiative in implementing the curricula & $(17,20)$ \\
\hline $\begin{array}{l}\text { Internal quality of the curriculum (teaching method, evaluation method, quality of content, the relationship between theory and } \\
\text { practice, quality of inputs and quality of processes) }\end{array}$ & $(14,17,18,22,23)$ \\
\hline Developing entrepreneurial characteristics and skills in students & $(10,16)$ \\
\hline Profound and active learning & $(13,22,24)$ \\
\hline Dimension of External Effectiveness & Reference \\
\hline Fulfilling the goals and values of the education system & $(3,14,19)$ \\
\hline Facilitating learning and changing learners' behavior at the work environment & $(24,25)$ \\
\hline Adaptability of the curriculum to varying environmental conditions, needs and requirements & $(19,22)$ \\
\hline Responding to the external environment & $(16)$ \\
\hline Satisfactory performance of the learners in the environment & $(18,21)$ \\
\hline Values and quality of the curriculum outputs & $(5,16)$ \\
\hline Improving the skills and capabilities of the learners (developing learners' competencies) & $(11,20)$ \\
\hline Dimension of External Effectiveness (Institutional Effectiveness) & Reference \\
\hline Fulfilling the social goals and ideals of the curriculum & $(3,16,18,26,27)$ \\
\hline Playing a role in social development and national self-sufficiency & $(3,16,22)$ \\
\hline Satisfactory performance and reformation of the education system & (27) \\
\hline Improving the external image and the strategic success of the (medical education) curriculum & $(16,22)$ \\
\hline Promoting human and moral virtues in the community & $(22)$ \\
\hline
\end{tabular}

to address the strategic approach requiring a focus on the two components of environment and future (16). Medical education institutions basically serve as strings that transfer the fields and confirm the content of specialties. Meanwhile, the mission of the medical education curriculum is extremely important. In fact, medical education curricula must be effective and help fulfill the goals and missions of medical education according to environmental complexities and dynamics. Effectiveness of this kind of curricula depends on meeting the environmental needs and considering the future of the medical education system (16, 19). This goal can be achieved by concentrating on the resources and the guiding role of strategies and the activi- ties of the medical education system. A review of literature helped derive a conceptual model for evaluating the curricula effectiveness using a strategic approach while considering all the dimensions and components of the curriculum based on environmental requirements, i.e. complexities and dynamics.

According to this approach, universities must be well aware of the basic needs and demands. A large part of the needs are obviously met through the curricula and proper teaching at universities by professors in the form of the materials and the curriculum content. Furthermore, the strategic approach seeks to change and develop the curricula as per the goals and missions of the medical education 
system $(3,4,14,28)$. The need for focusing on curriculum studies stems from the interdisciplinary approach used. To fulfill this goal, visionary, insightful, committed and specialized experts knowledgeable in the area of philosophy of interdisciplinary sciences should be asked to help with curriculum studies. Experts believe that the presence of innovative and pioneering ideas for improving the status of universities and consequently the curricula strengthens the positive aspects of strategic planning.

The reformation and professional empowerment of students is the fundamental and ultimate goal of the medical education system. In this regard, teaching/learning method, quality and organization of the content, teaching methods, access to competent and knowledgeable professors specialized in their field, considering environmental competitions and opportunities, presence of an interactive environment for the beneficiaries, i.e. satisfaction, mood, teacher/student relationship and behavioral interactions $(3,21)$, internal coherence and adaptation between the dimensions and components of the curriculum, i.e. adapting curriculum to the goals, content, teaching/learning methods and evaluation methods, and flexibility and innovation $(16,18,22)$ in curriculum implementation ensure the internal quality of the curricula and consequently create real values according to the goals and missions of medical education.

Evaluating the internal effectiveness of curriculum based on a strategic approach refers to fulfilling the aforementioned process in a systematic, integrated and dynamic fashion. Certain dimensions and components of the curriculum in a dynamic, interactive, coherent and multidimensional relationship thus fulfill the ideals of the medical education system from different internal and external viewpoints. The outcome would be developing knowledge, insight, attitude and skills of the beneficiaries caused by facilitating and deepening of learning that in turn changes student behavior. It is worth noting that adaptability of the curriculum to varying environmental conditions, needs and requirements results in learners' satisfactory performance, values and quality of the curriculum outputs, acquiring competencies $(14,17,19,27)$ and proper responses to the external environment $(14,19)$, as the consequence of evaluating the curricula effectiveness. Components contributing to the effectiveness of medical education curricula based on a strategic approach include the proportion and overlap among theoretical and applied sciences, problem-solving ability, acquiring communication skills, personality growth, acquiring critical thinking skills, the ability to deal with crisis as well as civil rights.

Research suggests that the prerequisite for ensuring the external effectiveness is to certify the internal effectiveness (16), and that the association and alignment of inter- nal and external types of effectiveness definitely lead to positive results in the community, which lead to playing effective roles in social development and consequently national and international self-sufficiency through reforming the education system $(16,22,26)$. In fact, evaluating the curriculum effectiveness at the institutional level leads to improving the external image (22) and a strategic success of medical education. The ultimate goal of the medical education system, i.e. promoting human and moral virtues (22) or educating decent individuals, is therefore fulfilled. Concentrating on the cited concepts helps establish an innovative education system through taking certain measures such as determining the goals at different levels. The result of taking such thoughtful measures is adjusting knowledge and skills, professional accountability, promoting the spirit of change, flexibility, adaptability to the changing environment, optimal use of the resources, receiving feedbacks on the effectiveness of the implemented programs to modify or clarify the goals or strategic selections and decisions.

\subsection{Conclusion}

When evaluating the curriculum effectiveness using a strategic approach, emphasis should be placed on environment-oriented education and development of education power of response to the environment and its various products, and the needs and contingencies of the present and future environment. In other words, the effectiveness of medical education curriculum can be considered a triangular system comprising three levels, including internal, external, and institutional effectiveness with a strategic approach orientation. These levels continuously interact one another and form a comprehensive framework for analyzing, explaining and evaluating the effectiveness of medical education curricula based on a strategic approach. Considering the simultaneous interaction of these levels of effectiveness according to their nature, definition and components, medical education curriculum and its effectiveness will lead to environmentalism, future orientation, contemplation and dynamism. As a result of such an action, the knowledge, insight, attitude and skill of all beneficiaries will be developed by facilitating and deepening learning that changes learners' behavior in line with effective responses to the conditions, needs, requirements, and contingencies of the strategic environment (Figure 1).

Based on the conceptual model proposed and the research results, responding to the varying and indeterminate environment is the strategic approach principle. Given that the future environment is strategic, dynamic and complex, using a strategic approach should be considered a fundamental principle so that the proper per- 


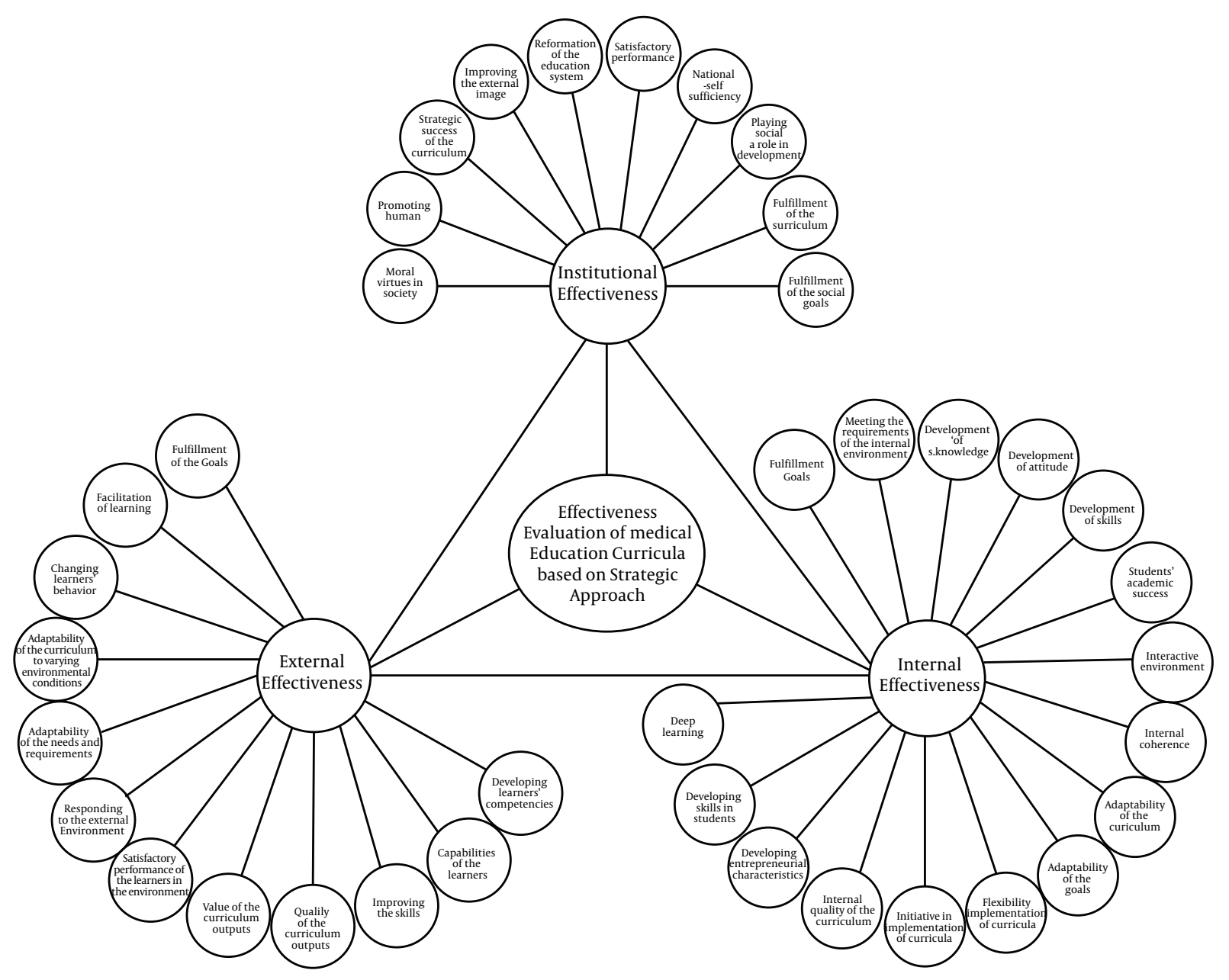

Figure 1. A conceptual model for evaluating the effectiveness of medical education curricula

formance of the university with regard to environmental requirements and its success and effectiveness as well as adaptation and compatibility and in general accountability will be ensured. In fact, the essential elements of the strategic approach include continuous qualitative changes and development of different dimensions and elements from different aspects.

\section{Footnotes}

Conflict of Interests: None declared.

Funding/Support: None declared.

\section{References}

1. Boyd D, Goldhaber D, Lankford H, Wyckoff J. The effect of certification and preparation on teacher quality. Future Child.2007;17(1):45-68. doi: 10.1353/foc.2007.0000. [PubMed: 17407922].

2. Enders J, Kehm BM, Schimank U. Turning universities into actors on quasi-markets: How new public management reforms affect academic research. In: Jansen D, Pruisken I, editors. The changing governance of higher education and research. Higher Education Dynamics. 43. Springer, Cham;2015. p. 89-103. doi:10.1007/978-3-319-09677-3_5.

3. Torkzadeh J, Nekoumand S. [Validating the scale of university's power of response to environment].Asian JRes Soc Sci Humanit. 2015;5(8):24152. Persian.

4. Hicks O. Curriculum in higher education in Australia-Hello. In Enhancing Higher Education, Theory and SCHOLARSHIP, Proceedings of the 30th HERDSA Annual Conference [CD-ROM]. 2007 Jul.

5. Soare E. Perspectives on designing the competence based curriculum. Procedia Soc Behav Sci. 2015;180:972-7. doi: 10.1016/j.sbspro.2015.02.259.

6. Mooiman MB, Sole KC, Kinneberg DJ. Challenging the traditional hydrometallurgy curriculum-an industry perspective. Hydrometallurgy. 2005;79(1-2):80-8. doi:10.1016/j.hydromet.2004.11.013.

7. Dehghani M, Pakmehr H, Jafari Sani H. Managerial challenges of curriculum implementation in higher education. Procedia Soc Behav Sci. 2011;15:2003-6. doi: 10.1016/j.sbspro.2011.04.043. 
8. Durib MJ. Challenges of globalization to school curricula from the point of view of faculty members with suggestions of how to deal with it. Procedia Soc Behav Sci. 2014;112:1196-206. doi: 10.1016/j.sbspro.2014.01.1284.

9. Crujeiras B, Jiménez-Aleixandre MP. Challenges in the implementation of a competency-based curriculum in Spain. Think Skills Creat. 2013;10:208-20. doi: 10.1016/j.tsc.2013.07.001.

10. Hökkä P, Eteläpelto A, Rasku-Puttonen H. Recent tensions and challenges in teacher education as manifested in curriculum discourse. Teach Teach Educ. 2010;26(4):845-53. doi:10.1016/j.tate.2009.10.022.

11. Bolstad R. School-based curriculum development: Redefining the term for New Zealand schools today and tomorrow. The New Zealand Association for Research in Education (NZARE) conference. 2004. 26 p.

12. Medbery RL, Sellers MM, Ko CY, Kelz RR. The unmet need for a national surgical quality improvement curriculum: A systematic review. J Surg Educ. 2014;71(4):613-31. doi: 10.1016/j.jsurg.2013.12.004. [PubMed: 24813341].

13. Karami M, Fatahi H. [The change of curriculum of higher education Master's curriculum in educational planning].J Curriculum Stud High Educ. 2013;4(4):7-28. Persian.

14. Arefi MS, Fathivajarghah K, Nasaj S. [Effectiveness of teaching entrepreneurship secondary vocational branch]. J Occup Organ Consult 2010;4(2):47-21. Persian.

15. Marzooghi R. [Curriculum sciences (new and future development)]. Tehran: Avaya Noor publication; 2015. Persian.

16. Torkzadeh J, Majidi A, Noormohammadi H. [Assess the effectiveness of the external curriculum significant degree military police platoon] Police Manag Stud. 2009;4(4):461-81. Persian.

17. Hart PL, Brannan JD, Long JM, Maguire MB, Brooks BK, Robley LR. Effectiveness of a structured curriculum focused on recognition and response to acute patient deterioration in an undergraduate BSN program. Nurse Educ Pract. 2014;14(1):30-6. doi:10.1016/j.nepr.2013.06.010. [PubMed: 23867283].

18. Miskel CG, Hoy WK. Educational administration: Theory, research, and practice. New York: McGraw-Hill Companies, Inc; 2001.

19. Thompson ME, Harver A, Eure M. A model for integrating strategic planning and competence-based curriculum design in establishing a public health programme: The UNC Charlotte experience. Hum Resour Health. 2009;7:71. doi: 10.1186/1478-4491-7-71. [PubMed: 19671160]. [PubMed Central: PMC2734530].

20. Torkzadeh J, Mohammadi M, Ghasemighasemvand M. [Assess the effectiveness of internal, external and institutional education system Arvand Petrochemical company,]. Humanit Arts. 2014;4(1):41-54. Persian.

21. Blackmore P, Kandiko C. Strategic curriculum change: Global trends in universities. Routledge; 2012. doi: 10.4324/9780203111628.

22. Torkzadeh J, Keshavarzi F. [The effectiveness of medical education curriculum: Internal, external and institutional].J Educ Dev Jundishapur. 2015;7(1):10-21. Persian.

23. Jacobs PM, Koehn ML. Curriculum evaluation. Who, when, why, how? Nurs Educ Perspect. 2004;25(1):30-5. [PubMed: 15017798].

24. Slavcev RA, Tjendra J, Cheung D. A model of iterative outcomebased curriculum design and assessment for strategic pharmacy education in Canada. Curr Pharm Teach Learn. 2013;5(6):593-9. doi: 10.1016/j.cptl.2013.07.008.

25. Goette T, Woodard H, Young D. The link among strategic planning, curriculum management, and assurance of learning: One school's experiences. Commun IIMA. 2008;8(2):31-45.

26. Mohammadi M, Naseri R, Moeni H. [The effectiveness of the external Curriculum Project Management Institute of Shiraz Electronic Industries: Based on the merits]. J Eng Educ. 2012;53(14):83-117. Persian.

27. Mohammadi M, Nseri R, Moeni H. [Internal efficiency and external effectiveness of medical professional curriculum of the students, graduates and faculty members Yazd University of Medical Sciences Shahid Sadoghi]. Iran J Med Educ. 2013;1(10):20-32. Persian.

28. Goldfinch TL, Carew AL, Cook CD, Olivares P, Cooper P, McCarthy TJ, et al. Initiating curriculum review: The chilean experience. Australasian Association for Engineering Education Conference. 2007. p.1-8. 